\title{
Research on Fuel-Dilution Monitoring of Engine Lubricant by FT-IR Spectroscopy
}

$$
\text { Gong Xiaolong }{ }^{1, a} \text {, Tian Hongxiang }{ }^{2, b} \text {,Sun Yunling }{ }^{3, c} \text {, Li Jing }{ }^{4, d}
$$

${ }^{1}$ College of Power Engineering, Naval University of Engineering, Wuhan 430033, P. R. China

${ }^{2}$ College of Power Engineering, Naval University of Engineering, Wuhan 430033, P. R. China

${ }^{3}$ College of Power Engineering, Naval University of Engineering, Wuhan 430033, P. R. China

${ }^{4}$ College of Power Engineering, Naval University of Engineering, Wuhan 430033, P. R. China

$$
\begin{aligned}
& \text { axlgong20140707@163.com, } \\
& \text { 'chxtianwuhan@aliyun.com, } \\
& \text { 'Sunyunling315@163.com, }{ }^{d} \text { Leejing0820@163.com }
\end{aligned}
$$

Keywords: FT-IR spectroscopy, fuel dilution, lubricant, oil monitoring

Abstract. FT-IR spectroscopy provides a measurement for fuel dilution in engine lubricating oil. Quantitative analysis techniques such as peak height and peak area could be employed in the analysis program of FT-IR spectroscopy. The accuracy of peak height method and peak area method is compared.

\section{Introduction}

With the development of computer technology, the application of oil analysis by FT-IR spectroscopy became relatively commonplace for production oil analysis laboratories ${ }^{[1]}$. Now FT-IR spectroscopy technology is widely used in the detection of lubrication oil, analyze the important parameters of lubricating oil in water, fuel dilution, ethylene glycol, carbon deposition, oxidation, nitration and antioxidant concentration ${ }^{[2,3]}$.

\section{Experimental device and materials}

The apparatus used Agilent Cary 630 FT-IR spectrometer which works at $600 \mathrm{~cm}^{-1}$ to $5100 \mathrm{~cm}^{-1}$. Figure 1 shows the Agilent Cary 630 FT-IR spectrometer.

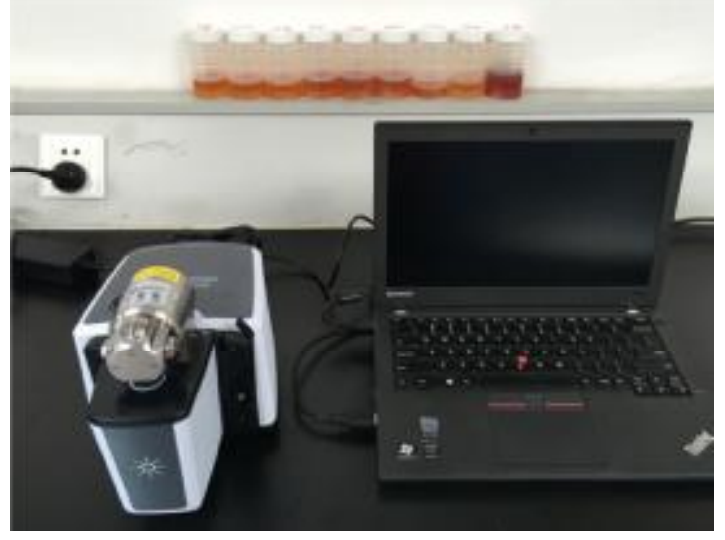

Fig. 1 Agilent Cary 630 FTIR spectrometer 
The Shell CD15W-40 lubricating oil is diluted with 0\# diesel fuel. Table1 show the oil samples.

Table1 Dilution of oil samples

\begin{tabular}{|c|c|c|c|}
\hline No. & $\begin{array}{c}\text { Diesel fuel quality } \\
(\mathrm{g})\end{array}$ & Lubricating oil quality $(\mathrm{g})$ & Percentage of diesel fuel (wt\%) \\
\hline 1 & 10.176 & 40.001 & 20.3 \\
\hline 2 & 5.005 & 45.003 & 10.0 \\
\hline 3 & 2.502 & 47.507 & 5.0 \\
\hline 4 & 1.246 & 48.750 & 2.5 \\
\hline 5 & 0.735 & 49.274 & 1.5 \\
\hline 6 & 0.355 & 49.685 & 0.7 \\
\hline 7 & 0.000 & 50.231 & 0.0 \\
\hline
\end{tabular}

\section{Results and discussion}

Obtained the spectra of seven oil samples with the Agilent Cary 630 FT-IR spectrometer, and showed in a coordinate system. Figure 2 show the infrared spectra of the oil samples have no significant change on most of the wave number. But in the range of $800 \mathrm{~cm}^{-1}$ to $825 \mathrm{~cm}^{-1}$, there is a significant change.

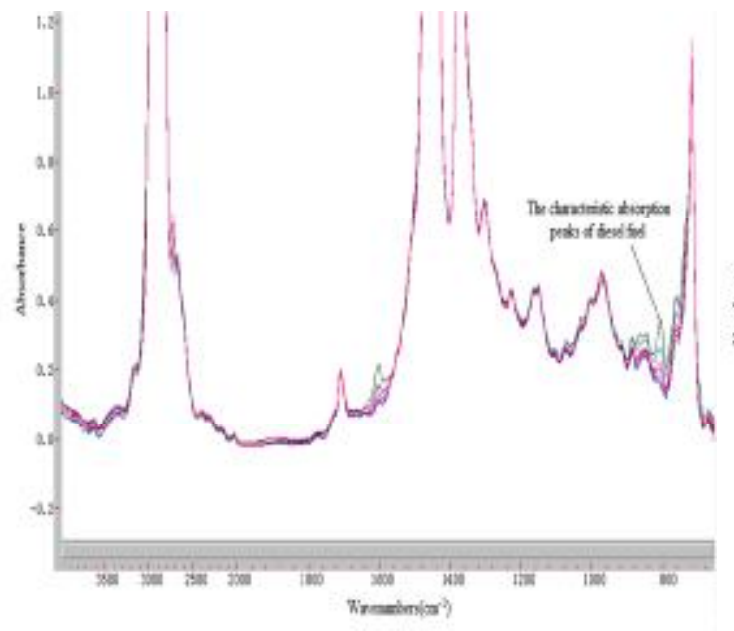

Fig. 2 The FTIR spectra of all oil samples

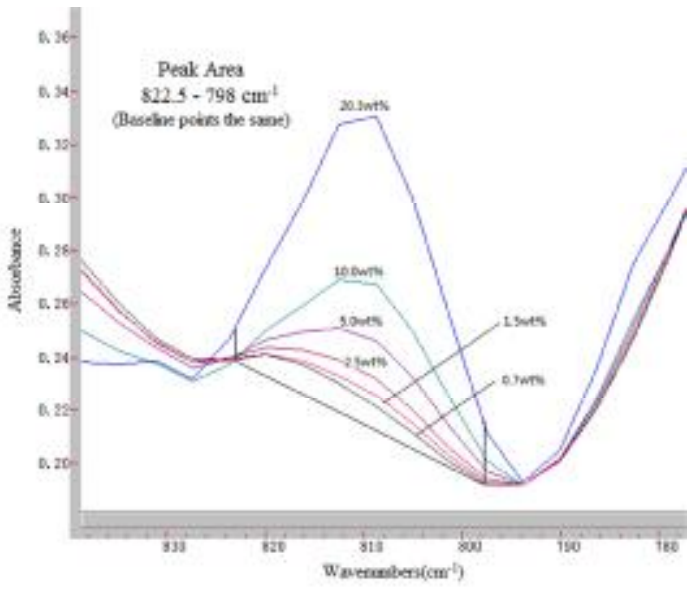

Fig. 3Spectra of oil samples

A marker band typical in diesel-contaminated samples is found at $809.98 \mathrm{~cm}^{-1}$. Baselines points are taken as the minima between $835 \mathrm{~cm}^{-1}$ to $820 \mathrm{~cm}^{-1}$ (left) and between $805 \mathrm{~cm}^{-1}$ to $795 \mathrm{~cm}^{-1}$ (right) [4]. The area is measured over the range of $822.5 \mathrm{~cm}^{-1}$ to $798.0 \mathrm{~cm}^{-1}$.

FT-IR spectroscopy determines fuel contamination by measuring the absorbance bands of specific components in the fuel. Quantitative analysis measurement techniques such as peak height and peak area could be easily employed in the analysis program of FT-IR spectroscopy.

The peak height of the oil sample in the wave number is $809.980 \mathrm{~cm}^{-1}$ as the arguments and the fuel concentration is the dependent variable. The fitting equation of peak height (h) with fuel concentration(c) is acquired.

$\mathrm{c}=173 . \mathrm{h}-0.614$ 
This fitting equation displayed good correlation $\left(\mathrm{R}^{2}=0.9962\right)$ between peak height and fuel concentration. Figure 4 show the fitting line of peak height.

The peak area of the oil sample over the range of $822.5 \mathrm{~cm}^{-1}$ to $798.0 \mathrm{~cm}^{-1}$ as the arguments, and the fuel concentration is the dependent variable. The fitting equation of peak area (a) with fuel concentration(c) is acquired.

$\mathrm{c}=10.9 \mathrm{a}-1.479$

This fitting equation displayed good correlation $\left(\mathrm{R}^{2}=0.9968\right)$ between peak area and fuel concentration. Figure 5 show the fitting line of peak area.

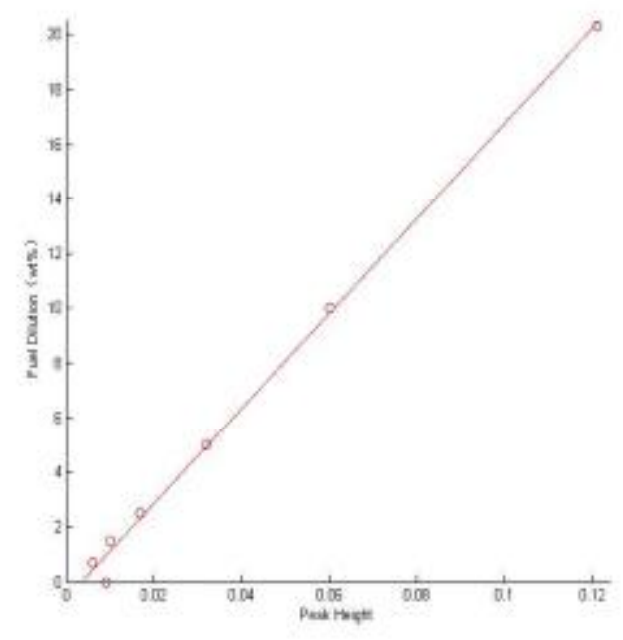

Fig. 4 The fitting line of peak height

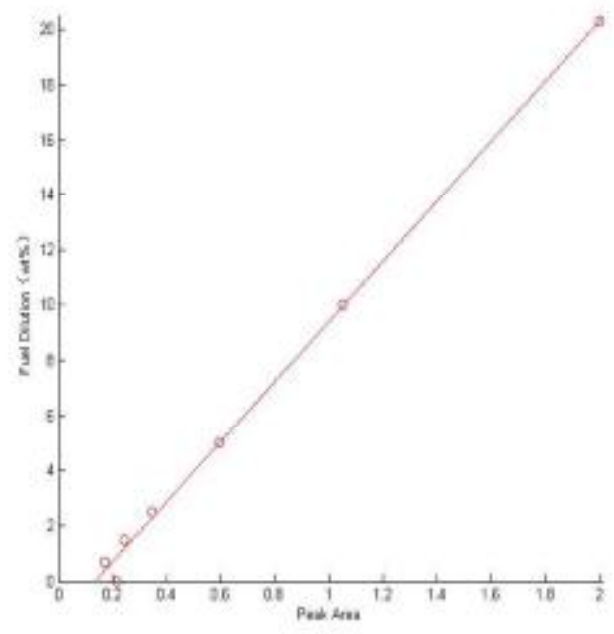

Fig.5 The fitting line of peak area

The relative error of the oil samples is calculated by comparing the peak area method and the peak height method.Table2 show the relative error of the oil samples.

Table 2 The relative error of the peak height and area of oil samples

\begin{tabular}{|c|c|c|c|c|c|}
\hline \multirow{2}{*}{ No. } & \multirow{2}{*}{$\begin{array}{c}\text { Actual } \\
\text { fuel content } \\
(\mathrm{wt} \%)\end{array}$} & $\begin{array}{c}\text { Fuel content } \\
(\mathrm{wt} \%)\end{array}$ & $\begin{array}{c}\text { Relative error } \\
(\%)\end{array}$ & $\begin{array}{c}\text { Fuel content } \\
(\mathrm{wt} \%)\end{array}$ & $\begin{array}{c}\text { Pelative error } \\
(\%)\end{array}$ \\
\cline { 3 - 6 } & 20.3 & 20.40 & 0.5 & 20.33 & 0.2 \\
\hline 1 & 10.0 & 9.81 & 1.9 & 9.97 & 0.3 \\
\hline 3 & 5.0 & 4.94 & 1.2 & 5.03 & 0.6 \\
\hline
\end{tabular}

The relative error of the peak area method is smaller than the peak area method. So peak area method for the detection of fuel dilution with high accuracy.

\section{Conclusion}

FT-IR spectroscopy for detection of fuel dilution with the peak height method and the peak area method, and the fitting equations are obtained. By comparing the relative error of the peak area method and the peak height method, the accuracy of the peak area method is higher.

\section{Acknowledgements}

This work was financially supported by the Hubei Province Natural Science Foundation (2010CDB01505). 


\section{References}

[1] Larry A. Toms, Allison M. Toms: Machinery Oil Analysis. Society of Tribologists and Lubrication Engineers, (2008).

[2] Macián V, Tormos B, Gómez Y A, et al: Tribology Transactions, 2012, 55(6): 872-882.

[3] Akochi-Koble: THERMAL-LUBE INC POINTE-CLAIRE QUEBEC (CANADA), (1998).

[4] ASTM Standard E2412-10, Standard Practice for Condition Monitoring of In- Service Lubricants by Trend Analysis Using Fourier Transform Infrared (FT-IR) Spectrometry. New York: American Society for Testing and Materials, (2010) . 